\title{
A Framework of a Computerized Decision Aid to Improve Group Judgments
}

\section{Utpal Bose*}

Finance, Accounting and CIS Department, College of Business,

University of Houston Downtown, One Main Street, Houston, Texas, 77002, USA

E-mail: boseu@uhd.edu

*Corresponding author

\begin{abstract}
In organizations, groups of decision makers often meet to make judgments as a group on issues and tasks such as, hiring a person who best fits an open position. In such tasks called cognitive conflict tasks, where there is no conflict of interest, group members attempting to reach a common solution often differ on their perspectives to the problem. Cognitive conflicts have been studied in the context of Social Judgment Theory, which posits that persons or judges make a set of judgments about a set of events based on observation of a set of cues related to the events. Disagreement arises because the judges fail to understand each other's judgment making policies. In order to reduce disagreement and move the group towards a group judgment policy that has the consensus of the group members and is applied consistently, a computerized decision aid is proposed that can be built around a Group Support System using cognitive mapping as a method of providing cognitive feedback and the Analytic Hierarchy Process to process the conflicting criteria and help an individual formulate a judgment policy, as well as aggregate the individual policies into a group judgment policy. It is argued that such as decision aid by supporting every decision maker in the group to effectively use information about the task so that they have a good understanding of the judgment policy they form, to communicate their evaluation policies accurately to other members, and by providing an iterative mechanism through which members can arrive at a compromise solution to the task, is expected to improve the quality of group judgments.
\end{abstract}

Keywords: Cognitive conflict, Group judgment, Cognitive map, Group support system.

Biographical notes: Utpal Bose researches in Group Support Systems, Decision Support and Expert Systems, Electronic Commerce, Strategic Information Systems, and End User Computing. His research articles have been published in Omega: The International Journal in Management Science, Journal of Group Decision and Negotiation, Society of Advanced Management Journal, and Journal of Information Technology among other journals. He has presented several research papers in national and international conferences. 


\section{Introduction}

Although group decision making has been conceptualized as a social process which takes individual preferences and aggregates them into a single group preference, achieving consensus is not always easy. Every group member brings a set of beliefs and values that were formed from previous knowledge and experience. These beliefs and values influence the processing of information by the member and may render the individual unable to process information consistently and to understand the positions taken and judgments made by other members about decision issues (Sherman et al. 1998). This incapacity results in conflict, disagreement, and misunderstanding among group members, often leading to decisions that are of low quality, or even failure of the group to arrive at a consensus decision (Cook and Hammond 1982).

Such situations are very likely to occur when a group works on tasks that have been classified by McGrath (1984) as involving cognitive conflict tasks. In cognitive conflict tasks, group members attempting to reach a common solution often differ in their underlying cognitive views of the problem, and have different preferences. For example, while the members in a committee entrusted to hire a Systems Analyst in an Information Systems department will agree that the best matching candidate ought to be picked, they may differ on which criteria and the magnitude of those criteria make a person the best match to the position. Unlike conflicts of interest which arise primarily because of differences in stake holdings or motives among the group members, cognitive conflicts arise because the members view the problem from different perspectives, even when they have similar interests in achieving the goal [McGrath 1984). Perspective on a problem situation is dependent on values and beliefs of the individual which are not ordinarily stored in memory, but rather constructed with the aid of memorial and other information (Anderson 1986). Therefore, clarification of a person's value system should help improve the decision making process. Use of structured group interaction techniques delivered with the assistance of decision aids, computerized or otherwise, can then be expected to help clarify values, structure interactions, and diagnose problems thus reducing cognitive conflict and improve decision making.

In this paper we propose a framework of a group decision making process to find consensus solutions to cognitive conflict tasks. The process is structured and aided by a group support system (GSS) that integrates cognitive mapping and a multicriteria decision making (MCDM) technique. Cognitive mapping is used as a method for helping a decision maker understand his own perception of the task as well as those of the others, while MCDM is used to help an individual decision maker arrive at a decision as well as to aggregate the group members' decisions into a group decision. We also illustrate the proposed group decision making process with an example.

\section{Research Literature}

Cognitive conflict was introduced and explained by Hammond (1965) using Brunswik's theory of probabilistic functionalism (1955). Cognitive conflicts have been studied in the context of Social Judgment Theory (SJT) (Brehmer 1976), the theoretical basis of which is built upon Brunswik's theory and its descendant, the lens model (Hursch et al. 1964). The SJT model states that individuals evaluate complex environmental patterns or events on the basis of a variety of cues, but only probabilistically. That is, if a certain set of cues is present, a certain environmental condition is likely, but not surely, to occur. The SJT model involves a set of criterion events, a set of cues, and a set of judgments about those 
events, based on observation of those cues, by a set of judges. The model has four components: (a) an organizing principle by which cues, which are stimuli serving as indicators of those environmental events, are combined, often in a linear fashion; (b) weights that reflect the relative importance of various cues as used in various individual's judgments; (c) function forms that relate the cues to the environmental patterns and to the individual's judgments; and (d) the consistency or predictability with which cues predict events and judgments, given the proper function form (Brehmer 1976). When two or more judges are trying to arrive at an agreement on a common problem, their disagreement may be based on underlying differences in the structure of their judgments the way their cues are weighted, the organizing principle, and the function form. This pattern or structure of judgments is called the judge's judgment policy (McGrath 1984).

Tucker's (1964) version of the lens model equation consists of factors which are indicative of the extent of agreement between members of a dyad. Tucker's version of the equation is:

$$
\mathrm{r}_{\mathrm{A}}=\mathrm{GR}_{\mathrm{S} 1} \mathrm{R}_{\mathrm{S} 2}
$$

The result $\mathrm{rA}$ is the correlation between the judgments made by individual $\mathrm{S} 1$ and those made by individual S2. Therefore, rA is an index of the extent of agreement between $\mathrm{S} 1$ and S2. G indicates the extent of similarities between the judgment policies of S1 and S2. The factors RS1 and RS2 are multiple correlations between cues and judgments made by $\mathrm{S} 1$ and $\mathrm{S} 2$ respectively, thus measuring the consistency of judgment policies of each group member. Disagreement within the group may occur from two possible sources: (a) differing judgment policies amongst the members revealed by a low value of G, and (b) inconsistency by any one member in using a policy which is indicated by a low value of RS1 or RS2. According to the SJT model, most judgment policies may be represented as a linear combination of cues (Brehmer 1976). The linear model can be represented by

$$
\mathrm{y}_{\mathrm{i}}=\sum_{\mathrm{k}=1, \mathrm{~m}} \mathrm{~b}_{\mathrm{ik}} \mathrm{x}_{\mathrm{k}}
$$

where $y_{i}$ is the judgment of individual $i, m$ is the number of cues, $b_{i k}$ is the weight for individual $\mathrm{i}$ on cue $\mathrm{k}, \mathrm{x}_{\mathrm{k}}$ is the value of cue $\mathrm{k}$.

Besides the possible sources of cognitive conflict that can be deciphered from the SJT model, other sources of cognitive conflict may be traced to group process losses and the conflicting nature of multiple cues of the judgment problem as well as limited human information processing capability. Group process losses such as domination by a few group members, evaluation apprehension, and free riding in which members abstain from participating and rely on others to accomplish the task may suppress sharing one's cognitive orientation, thus holding back resolving cognitive conflicts. Group process gains, on the other hand, such as synergy where information shared in the group may be used successfully in a way that the original holder of the information may not have anticipated, and mirage detection in which groups are better at catching errors than individuals, can assist in clarifying misbelieve revealing cognitive orientations that is a step towards reducing cognitive conflicts. Multiple studies (Lim and Guo 2008) have shown that group support systems when designed appropriately can lower the group process losses while improving the group process gains. Uniqueness of information held by the group members impacts what information is shared more often in the group. Task relevant information that is common to all group members is exchanged more frequently than information that is unique to one person alone in GSS supported discussions. However, when individuals were role-assigned, GSS groups brought together more 
unique information (Vathanophas and Liang 2007). We expect role-assignment to improve revelation of cognitive orientations of individuals who may be apprehensive in sharing viewpoints that are not widespread.

Moving beyond the theoretical aspects of the SJT model, a few publications examined the effect of some form of intervention on cognitive conflict or judgment performance. Many of these studies involved the use of decision and communication aids in Information and Communication Technology (ICT) forms. Harmon (1998) studied the effects of decision making method and communication medium on group satisfaction and agreement, and found that audio-communication was more satisfying than face-to-face communication while structured interaction rather than computer-generated cognitive feedback led to more agreement than conventional decision method. Harmon and Rohrbaugh (1990) and Sengupta and Te'eni (1993) studied the effect of cognitive feedback on group judgment. While Harmon and Rohrbaugh found that individual judgments were more accurate and there was greater agreement in shared than reduced feedback condition, Sengupta and Te'eni reported that cognitive feedback increased cognitive control at both individual and group level but did not increase strategy convergence. While a group support system was found to improve the group judgment accuracy in a study done by Reagan-Cirincione (1994), two important measures of performance for group judgments - reduction in cognitive conflict and consistency of judgments - were not measured in that study and the group process did not attempt to utilize the benefits of a GSS. Bose and Paradice (1999) conducted a study in which a GSS consisting of cognitive feedback and multi-attribute utility (MAU) theory based multicriteria decision-making techniques that reduced disagreement between group members and improved consistency of judgments. The study used simple cognitive feedbacks such as displaying the individual decision maker's MAU charts to the whole group and a simple process to integrate the feedback and multicriteria decision making methods. We propose a more sophisticated process to integrate the feedback with the steps of forming individual judgment policies and aggregating those policies into a group policy in the framework presented in this paper. Another study that investigated the effect of GSS on cognitive conflict tasks was by Paul et al. (2004) in which collective memory information provided by GSS speeded up decision-making of cognitive conflict tasks.

Cognitive feedback has been provided with cognitive maps, which are graphic representations of cause and effect relationships between decision variables. Cognitive maps show how an individual relates to an information environment by providing a frame of reference for what is known and believed (Axelrod 1976). Cognitive mapping techniques such as, content analysis, causal mapping, repertory grids, matrices, and argument mapping are used to identify an individual's beliefs about a particular domain and to depict these diagrammatically (Fiol and Huff 1992). Cognitive mapping has been shown to help better understand the complexities in managing large construction projects (Edkins et al 2007), to analyze policies in the public sector by collating, comparing, and analyzing the views of many experts (Eden and Ackermann 2004), and to elicit knowledge from policy makers in order to build an inventory of knowledge required to develop complex policies for natural resource management (Jackson and Webster 2007) among several other applications.

Cognitive maps have been commonly categorized upon the purpose of the maps (Huff 1990). Five categories identified by Huff (1990) are: (a) maps that assess attention, association and importance of concepts, (b) maps that show dimensions of categories and cognitive taxonomies, (c) maps that show influence, causality and system dynamics, (d) maps that show the structure of argument and conclusion, and (e) maps that specify schemas, frames and perceptual codes. Attention maps (Category-a) associate frequent 
use of concepts (from the words used by the decision maker to describe those concepts) to important themes. Categories maps (Category-b) investigate more complex relationships among concepts and explore the range and nature of choices perceived by decision makers in a given setting. These maps will be useful when a group, in order to form the 'best' judgment policy, must explore a large variety of options that are beneficial to arrive at the consensus policy, and select the important ones for consideration. Causal maps (Category-c) lay out causal relationships between cognitive elements. So, causal maps are appropriate as cognitive feedback aids that will provide decision makers with better insight into their judgment policies. Cognitive feedbacks should attempt to show the logic behind conclusions and decisions to act so that other individuals can follow the arguments for another individual's judgment policy. Such feedback can be provided by argument maps (Category-d), which not only contain causal beliefs, but take a broader look at the domain as a whole to show the cumulative impact of various evidence and the links between longer chains as a whole. While there are many different approaches to capturing individual cognitive maps, only four of the approaches describe a method that produces collective cognitive maps (Tegarden and Sheetz, 2003). These are congregate maps (Bougon, 1992), shared maps (Langfield-Smith, 1992), group maps (Eden and Ackermann, 1998), and oval maps (Eden and Ackermann, 1998). Congregate maps are based on a map of a social system that is based on the individual maps that are created using the Self-Q technique (Bougon, 1983). Langfield-Smith (1992) created a shared map where the participants identified ideas from the individual cognitive maps that they could share. Next, they identified a set of relationships between the elements that they could agree upon, after which the individual maps were merged into a shared map. A group cognitive mapping methodology using a computer-based system has been demonstrated (Tegarden and Sheetz, 2003).

\section{Scheme of Group Judgment Making Process}

Now, we present and discuss architecture of a group judgment making process that integrates the communication and decision-support activities of GSS technology and the cognitive feedbacks provided by cognitive maps that is expected to reduce cognitive conflicts in groups leading to improved group judgments. The physical setting of the meeting involves the group members meeting in a room equipped for GSS supported meetings where each person sits at a computer all of which are networked and the seats are arranged in such a way that the group members can see each other and the facilitator (e.g., horse-shoe shape, oval shape). The facilitator positions herself at the head of the seating arrangement and has a computer and a public display system. The setting of our proposed GSS architecture does not use anonymous communication. Even though some researchers have posited that minimization of position differences and freedom from a fear of retribution brought about by anonymity may foster more open discussions, other studies reported mixed findings and that anonymity may actually undermine source credibility (Rains 2007).

The outline of the group judgment process is shown in Figure 1. It is divided into four phases. In phase A the cues that constitute the judgment policy are identified by each decision maker. The cues of all decision makers are compiled in phase B after which, in phase C, each decision maker adopts the group's agreed upon set of cues to construct his own judgment policy. Finally, in phase D the individual judgment policies are aggregated in an iterative process to arrive at the group's consensus judgment policy. In each phase the decision making process is aided by cognitive maps. 
Phase A

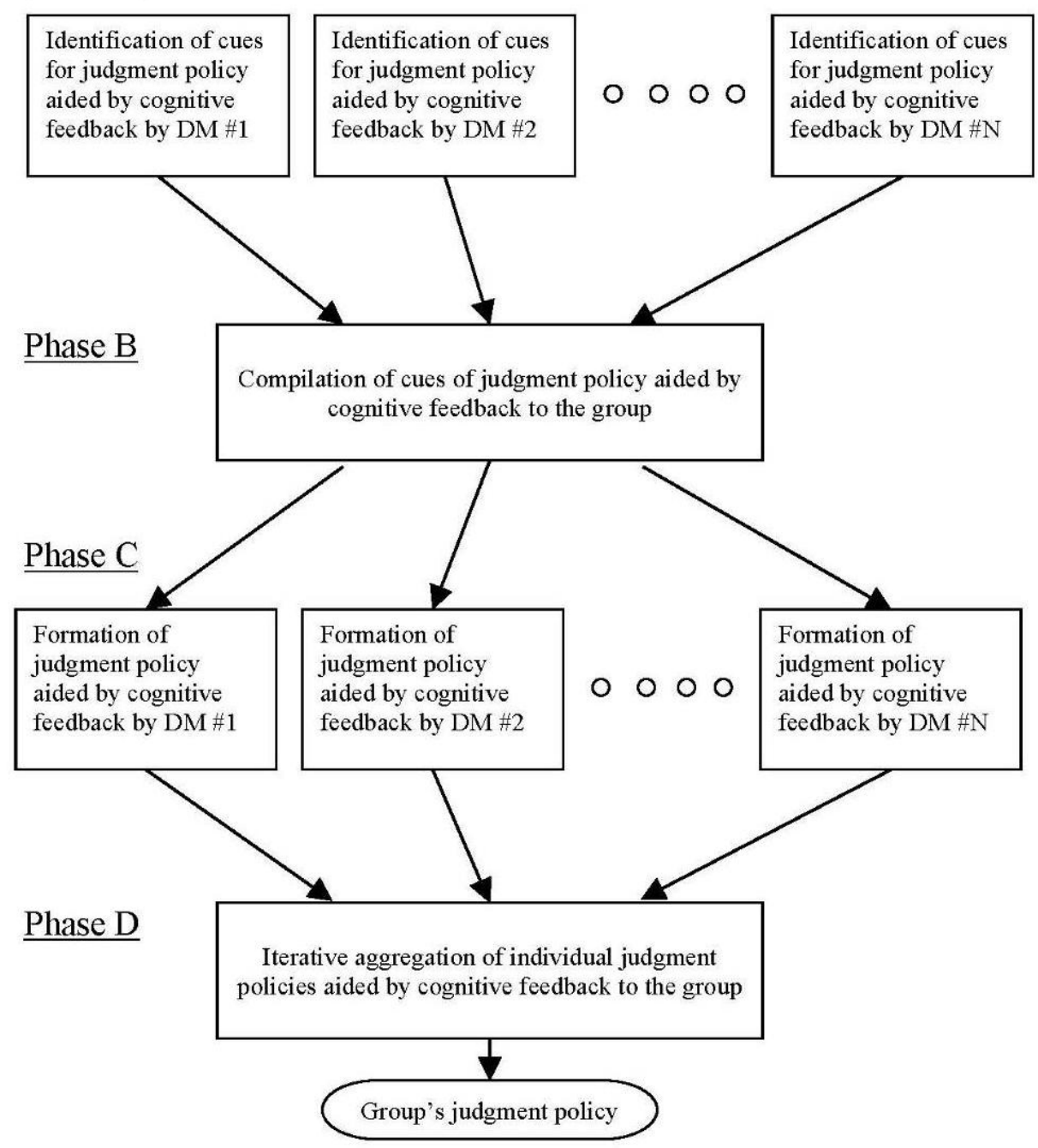

Figure 1. Outline of GSS-bases Architecture to Support Cognitive Conflict Tasks

\subsection{Phase A - Identification of Cues by Individual Decision Makers}

The meeting begins with the facilitator seeking the decision makers' beliefs and values concerning the policy being formulated. The decision makers respond by typing their comments on their computers, which are anonymously displayed on all participants' computer screens. This activity is indicated in box 1 of the flowchart for phase A shown in Figure 2. At the end of the free-flowing discussion, as determined by the facilitator, the transcript is analyzed with a content analysis software such as General Inquirer (Shapiro 1997) to identify the initial set of cues a decision maker thinks is relevant. The cues are displayed as a list, which is the attention map, to the decision maker to make him aware 
of the cues he believes to play a role in the decision problem being discussed (box 2 in Figure 2).

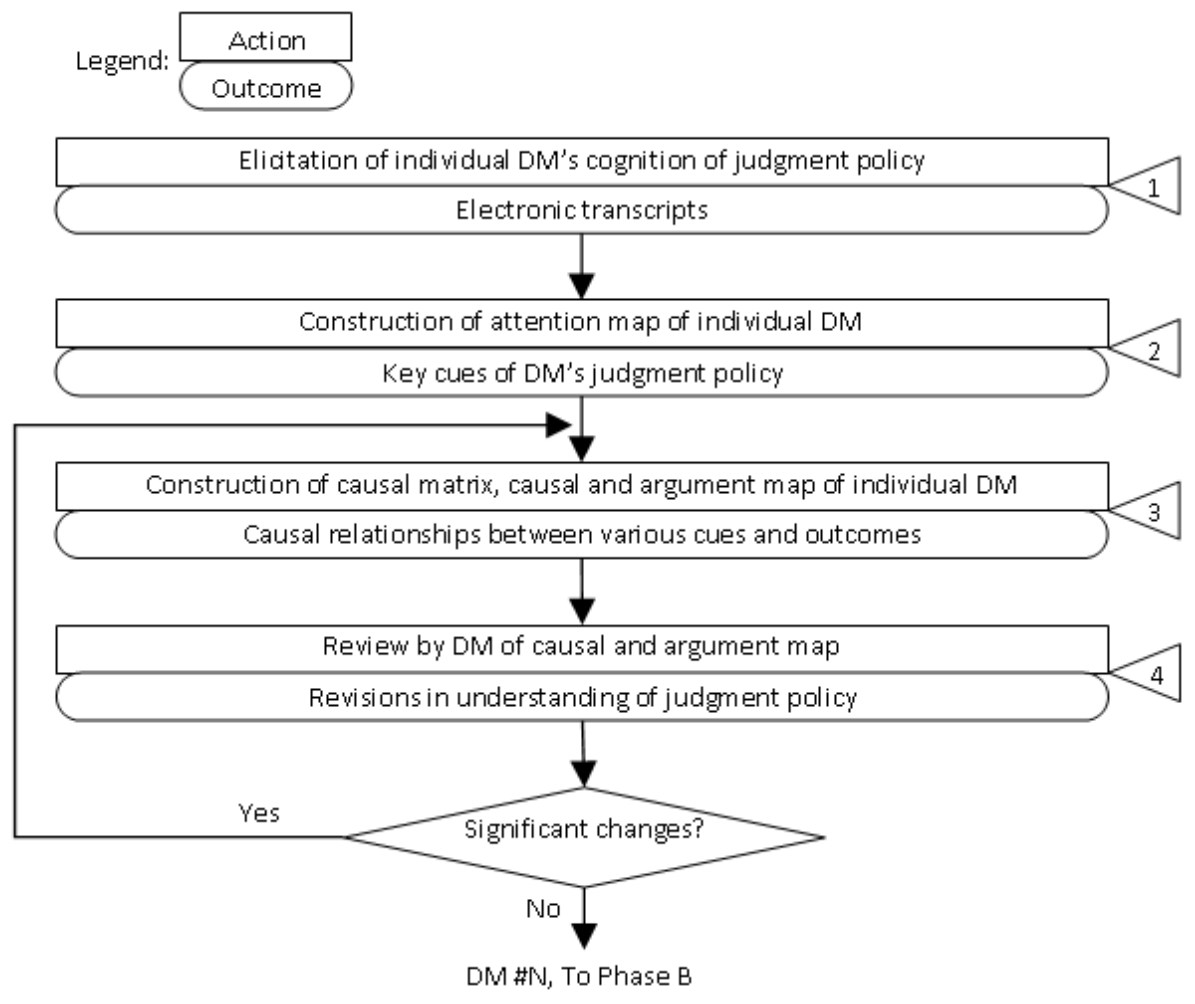

Figure 2. Flow Chart for Phase A

When an individual initially forms a judgment policy, visual feedback of the argumentation about policy issues that reveal or highlight the implications for the way the various cues or criteria enter the construction of the judgment policy is expected to assist him in understanding the policy. For this purpose, after the key cues have been brought to the decision maker's attention, the causal relationships between the various cues and between cues and outcomes are presented in causal and argument maps (box 3 in Figure 2). The causal and argument maps reveal the logic and assumptions that dominate the decision maker's claims and justifications for the links drawn between the nodes in the map (Fiol and Huff 1992). The cues and outcomes identified in the attention map become nodes in the causal and argument map. The information contained in a causal map can also be represented by a matrix in which all nodes are listed along the horizontal and vertical axes and the cells show the nature of the causal link (Axelrod 1976). An example causal matrix is show later in the paper in Figure 6 when we illustrate our group judgment making process. The intensity of the causal effects is assessed by asking each decision maker to indicate for each ordered pair of distinct nodes $\mathrm{x}$ and $\mathrm{y}$, whether (all other things being equal) node $\mathrm{x}$ significantly augments, inhibits, or has insignificant effect on node y. The intensity of effect can be included at three levels - weak, moderate, or strong. Next, a causal and argument map in the form of a signed digraph can be constructed from the matrix generated by the decision maker (Figure 11). Presenting the map to the decision maker is expected to assist him in understanding his judgment policy, and gives him the opportunity to focus on issues and fill in any missing information, 
remove extraneous information, or replace dated information with more relevant information (box 4 in Figure 2).

\subsection{Phase B - Compilation of Cues}

When all individuals have constructed their own maps we move on to phase B (Figure 3), where these maps are projected on the public screen so that all decision makers can share each other's map (box 5 in Figure 3). Drawing from each of the maps, a list of judgment cues is compiled which is then modified to eliminate cues that are similar in content but differently worded.

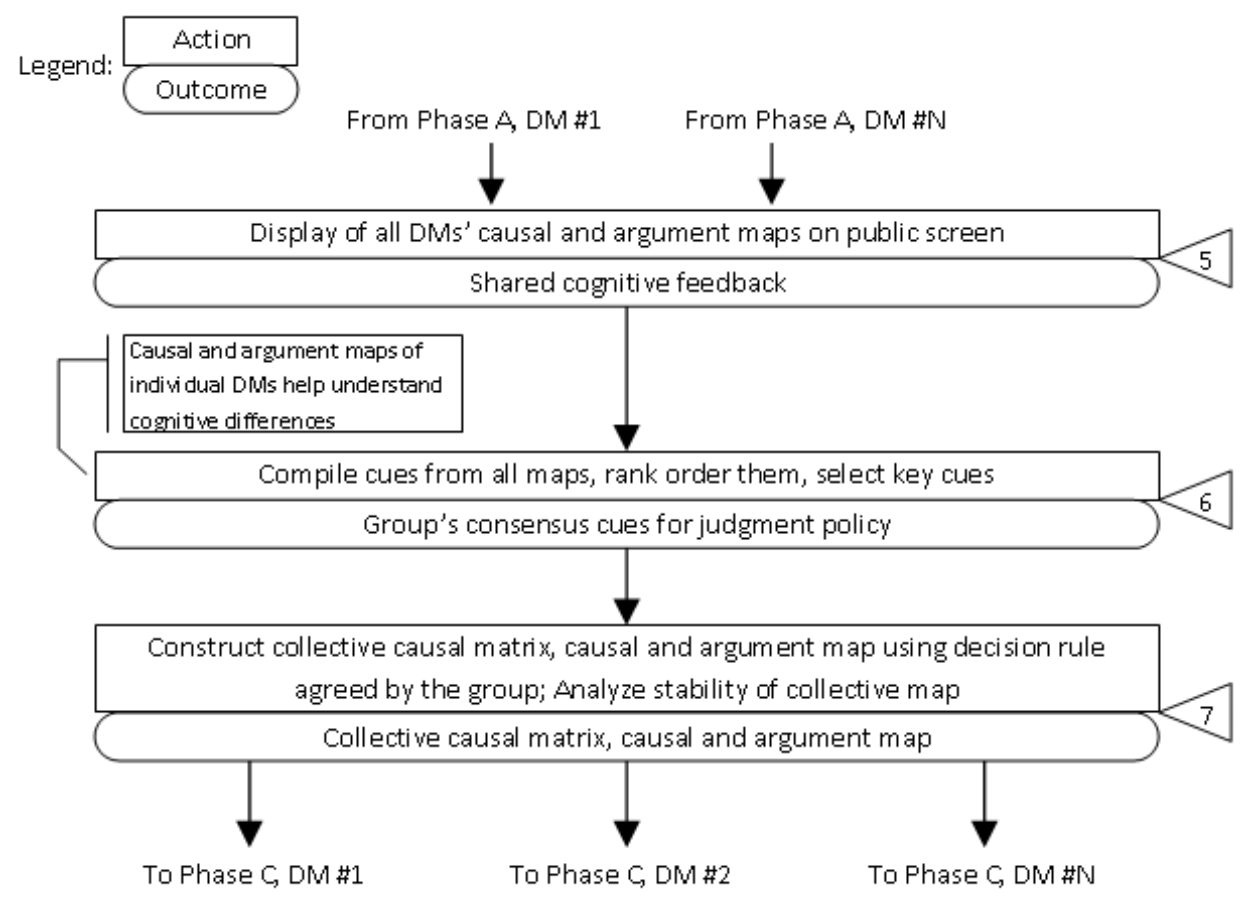

Figure 3. Flow Chart for Phase B

The cues are rank ordered by voting following which the group embarks on an electronic discussion to reduce the number of cues to only those that affect the outcome of the judgment policy significantly (box 6 of Figure 3). If the group wants to weight the votes of group members according to their position of power or level of expertise as perceived by other group members, then the Lehrer-Wagner voting scheme (Lehrer and Wagner 1981) may be adopted instead of the more common nominal voting scheme. The Lehrer-Wagner voting scheme is expected to provide a higher level of decision quality because it correlates the votes of decision makers with their level of competence/knowledge of the problem domain as perceived by other decision makers in the group (Fedrizzi and Pasi 2008).

The causal links in the maps help members understand others' policies, which, in turn, are expected to help the group arrive at a consensus list of cues that will go into the group judgment policy. A collective causal map of the group can be constructed by asking the members to rebuild the causal matrix with the agreed upon cues. To build the 
collective causal map in the form of a signed digraph, one must determine whether a connection exists between a given pair of nodes, and if so, what sign it has. The group has to set up decision rules such as, if seven out of ten members have indicated a relationship between two nodes, then connect the nodes and give it the sign agreed to by seventy percent of the respondents. Once the collective map is set up, it can be analyzed for stability, after which it is expected that the map will be accepted by the group reflecting it to represent the group's understanding of their judgment policy (box 7 in Figure 3).

\subsection{Phase $\mathbf{C}$ - Construction of Individual Judgment Policies}

The group causal and argument maps represent the skeleton structure on which the organizing principle of the judgment policies can be built. In phase C (Figure 4), the judgment policy is developed according to the SJT model, by first establishing a linear combination of weighted cues (box 8 in Figure 4).

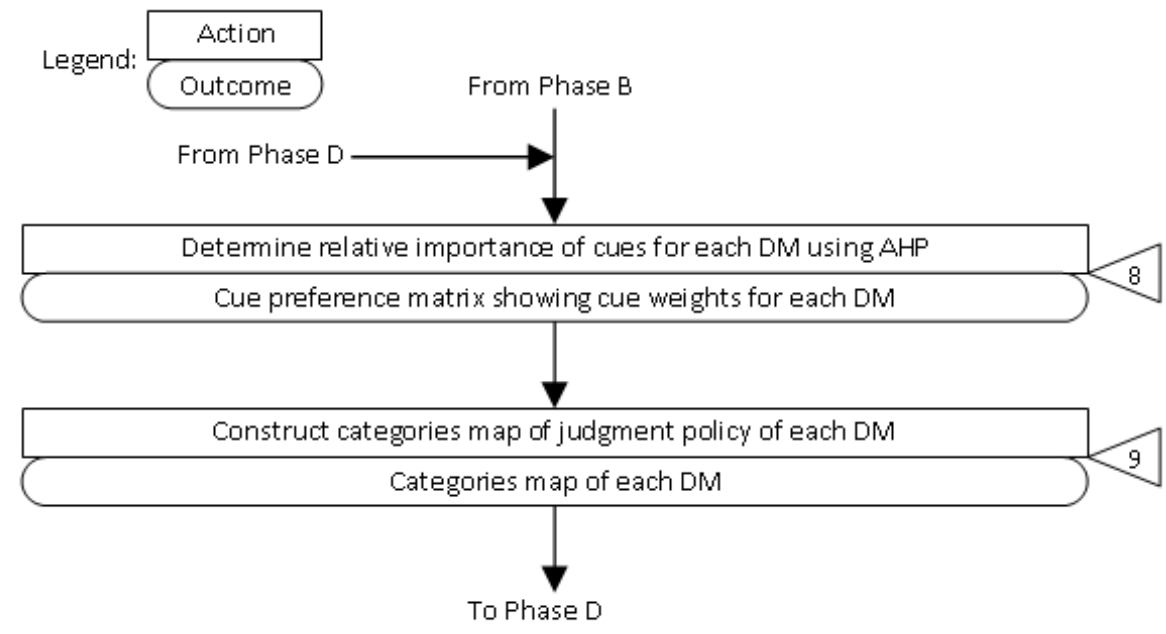

Figure 4. Flow Chart for Phase C

In the traditional method of analysis of an individual's cognitive system, the individual makes judgments about a representative set of cases of the judgment problem, where each case consists of a profile representing a different combination or mix of values on the several cues (Hammond 1966). The individual indicates her judgments by rating several profiles on a numerical scale, following which the judgments are analyzed by regression analysis to determine the regression weights that go into the linear model of this judgment policy as weights of corresponding cues. In the probabilistic environment of the judgment making process one has to establish compensatory balance, or in other words, the ability to substitute for and make trade-offs between cues (Hammond 1966). Since a large number of cues many of which conflicting in nature, may not be compared thoroughly due to limited human information processing capability, it is not known whether the regression weights truly reflect trade-offs between cues. The MCDM methods allow analyses of several criteria simultaneously and the criteria may be quantifiable or descriptive (Saaty 1980). Use of MCDM methods are particularly beneficial when the decision maker finds it hard to choose among the alternatives because none of the alternatives stand out clearly as best. We use the MCDM technique called the AHP method (Saaty 1980) to determine the individual decision maker's relative 
comparison of cues or criteria and the relevant weights, and also to obtain the aggregated criterion weights of the group. While other MCDM methods may be used too in this environment, we picked the AHP method because of its simplicity of use and our familiarity with this technique.

The first step in the MCDM method lets each decision maker state the relative importance of the criteria or cues. The individual makes pairwise comparisons between the cues by answering the question; "Consider optimizing cue $\mathrm{i}$ and optimizing cue $\mathrm{j}$ to maximize the benefits from the judgment policy. Which of the two cues would you deem more important, and by what ratio?" The scale of relative importance of the cues is the preference scaling method suggested by Saaty and Vargas (1982), and shown in Table 1. The eigenvectors and normalized eigenvectors are determined, following which the normalized eigenvectors are used as the estimated weights in the decision maker's judgment policy. The judgment policy of every individual decision maker is represented as

$$
\mathrm{y}_{\mathrm{ij}}=\sum_{\mathrm{k}=1, \mathrm{~m}} \mathrm{~b}_{\mathrm{ik}} \mathrm{x}_{\mathrm{jk}}
$$

where $\mathrm{y}_{\mathrm{ij}}$ is the judgment of alternative proposal $\mathrm{j}$ by individual $\mathrm{i}$ who fully understands the implications of the policy, $m$ is the number of cues identified in a consistent manner with the help of cognitive mapping, $b_{i k}$ is the weight for individual $i$ on cue $k$ determined by the AHP method which accounts for the conflicting nature of cues, and $\mathrm{x}_{\mathrm{jk}}$ is the value of cue $\mathrm{k}$ obtained from direct measurements of alternative proposal $\mathrm{j}$.

Table 1. Preference Scaling in AHP (Saaty 1980)

\begin{tabular}{|c|c|c|}
\hline $\begin{array}{l}\text { Intensity of } \\
\text { Importance }\end{array}$ & Defirition & Explanation \\
\hline 1 & Equal importance & Two cues have equal importance. \\
\hline 3 & Weak importance & $\begin{array}{l}\text { Experience and judgment slightly favor one over another } \\
\text { cue. }\end{array}$ \\
\hline 5 & Strong importance & $\begin{array}{l}\text { Experience and judgment strongly favor one over another } \\
\text { cue. }\end{array}$ \\
\hline 7 & Demonstrated & $\begin{array}{l}\text { A cue is strongly favored and its dominance is } \\
\text { demonstrated by important past experience. }\end{array}$ \\
\hline 9 & Absolute importance & Very strong evidence favoring one cue over another. \\
\hline $2,4,6,8$ & $\begin{array}{l}\text { Intermediate values } \\
\text { between adjacent scale } \\
\text { values }\end{array}$ & $\begin{array}{l}\text { Used when compromise is needed between adjacent scale } \\
\text { values. }\end{array}$ \\
\hline
\end{tabular}

Since the weights form an integral part of the judgment policy, reduction of cognitive conflict will require agreement among the members on weights, and complete understanding by individual members of the manner in which weights were selected so that they can use the judgment policy consistently. To assist the decision makers in understanding the cue weights arrived at by themselves and their fellow members, cognitive feedback is provided by means of a categories map that shows dimensions of categories and cognitive taxonomies (Fiol and Huff 1992) and can display the relative emphasis given to a large number of variables or cues. The categories map for our illustrated example is provided later in the paper in Figure 11. In the categories map each cue of a judgment policy is considered to be a vector and shown as an axis. The weights given to different cues or objectives by different decision makers are emphasized by connecting points on the corresponding vector. This creates for each decision maker a set 
of arcs generating a closed polygon, the shape of which indicates the emphasis placed by the individual on the various cues (box 9 in Figure 4).

\subsection{Phase D - Construction of Group Judgment Policy}

Iterative aggregation of judgment policies of individual decision makers to arrive at a consensus group judgment policy begins by combining the individual categories maps. The flowchart for this phase is shown in Figure 5. The polygon shaped categories maps of different individuals are superimposed on each other making it easy to view how the emphasis on the cues placed by the different decision makers differ (box 10 in Figure 5). After the cognitive feedback, all the members are given the opportunity to revise their estimates of the cue weights and are assisted with using the AHP method if they want to. The revised set of weights is displayed again on the categories map, and the decision makers are asked whether they would like to revise them again (box 11 in Figure 5). When they agree to continue with the set of weights determined, the group decision making proceeds into the final stage, which involves determination of the group cue weights (box 12 in Figure 5). This is done by first determining the geometric mean of the relative comparisons for each pairwise comparison made by every decision maker, which are then used as elements to construct the matrix of cues of the group as shown in Figure 12 later in the paper when we illustrate the process with an example. The normalized eigenvectors obtained from the matrix are the estimated weights of the cues of the group judgment policy. We now have a group judgment policy set up as a linear combination of cues according to the SJT model. The group judgment policy for a cognitive conflict task is represented as

$$
\mathrm{Y}_{\mathrm{j}}=\Sigma_{\mathrm{k}=1, \mathrm{~m}} \mathrm{~B}_{\mathrm{k}} \mathrm{X}_{\mathrm{jk}}
$$

where $Y_{j}$ is the judgment on alternative proposal $j$ formed by the group which fully understands the implications of the policy, $\mathrm{m}$ is the number of cues identified in a consistent manner with the help of cognitive mapping, $B_{k}$ is the group's weight on cue $k$ determined by the AHP method which accounts for the conflicting nature of cues, and $\mathrm{x}_{\mathrm{jk}}$ is the value of cue $\mathrm{k}$ obtained from direct measurements on alternative proposal $\mathrm{j}$. The group judgment making process is illustrated with an example in the following section. 


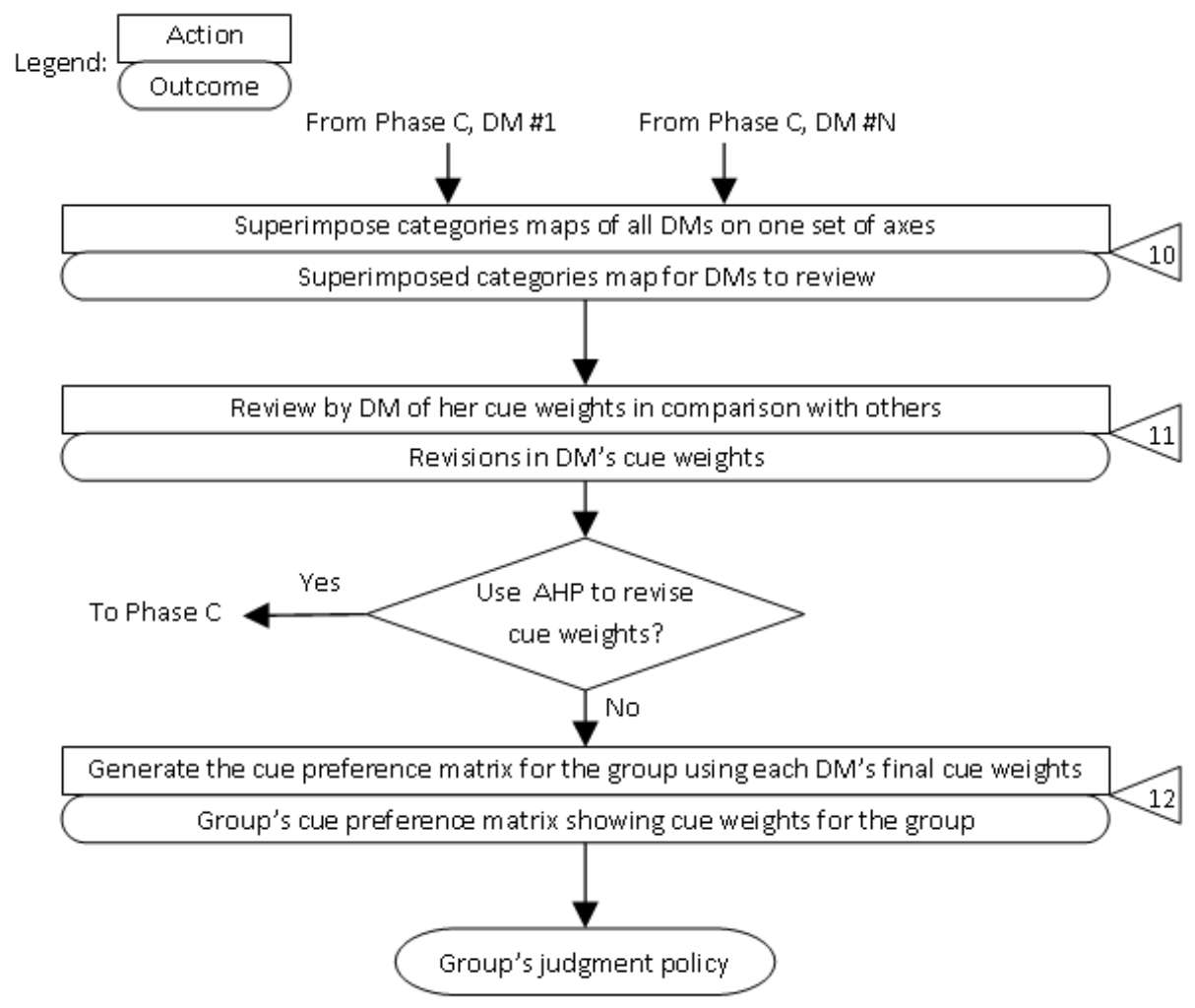

Figure 5. Flow Chart for Phase D

\section{Illustration}

In this section, we illustrate the approach developed above by an example wherein a hypothetical public policy for improving the community of a town is to be established. A first step will be to identify relevant characteristics or cues (or objectives), such as, public safety, economic development, education, and health. There could be more than one level of cues. For example, under economic development there could be (i) develop commerce that will bring money into the community, (ii) establish trade development that provides maximum convenience to consumers, and (iii) ensure optimal utilization of all land. All the decision makers are invited to a GSS-aided meeting where the facilitator elicits their beliefs and values concerning the policy being formulated in an anonymous setting. The transcripts are analyzed by a content analysis software package such as General Enquirer to identify the cues and create the attention maps of the participants. A hypothetical set of the identified cues is listed in Table 2. It is possible that some decision makers may put forward their beliefs and values in terms of lower level cues, which are usually more easily measurable. Then using a bottom-up approach, the lower level cues will have to be integrated hierarchically into a first level cue that finally fits into the judgment policy of the decision maker. 
Table 2. Preference Cues Generated by Attention Mapping

\begin{tabular}{cl}
\hline Cue & \multicolumn{1}{c}{ Description } \\
\hline 1 & Economic development \\
2 & Housing development \\
3 & Recreation programs \\
$J$ & Environmental management \\
Q-1 & Crime control
\end{tabular}

To provide a better understanding of the inter-relationships amongst cues and the effect of cues on a policy, a causal map in the form of a signed digraph is constructed for each decision maker in a two-step process. First, a causal matrix (Figure 6) is generated on the basis of a decision maker's revelations about relationships between the cues, followed by a signed digraph (Figure 7) that pictorially represents the causal matrix.

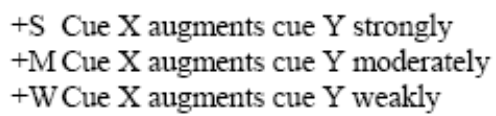

0 Cue $\mathrm{X}$ has insignificant effect on cue $\mathrm{Y}$

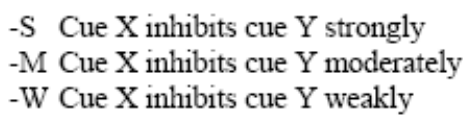

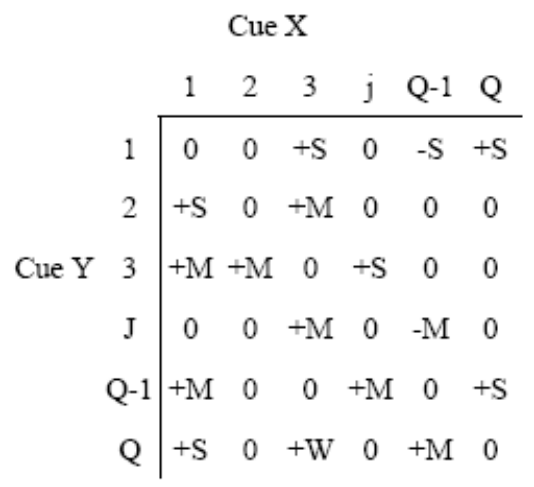

Figure 6. Causal Matrix of Individual Decision Maker (DM \#1)

The signed digraphs of decision makers are projected on a public screen and discussion ensues on the GDSS to build a consensus set of cues. The Lehrer-Wagner voting scheme may be used as a GDSS tool to rank order cues in order to arrive at a consensus set of cues. A decision rule to guide construction of the group's causal matrix is adopted by the group members, following which the matrix itself is built (Figure 8). The group causal matrix provides a clear understanding of the relationships between the cues which helps the decision makers to evaluate policies in the same problem domain consistently. The knowledge of the relationships between cues further helps the decision makers to carry out trade-off analysis between cues in the MCDM stage in a more informed manner. 
(1) Nodes represent cues

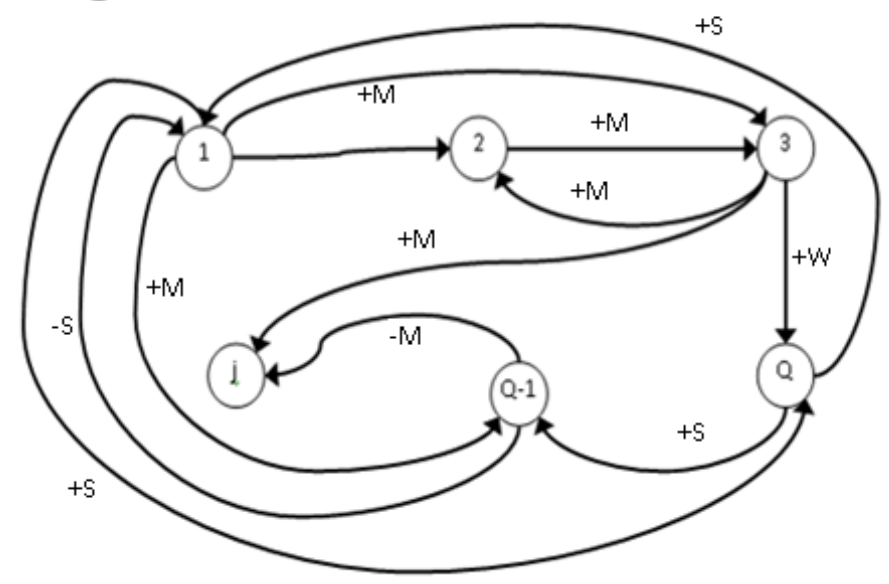

Figure 7. Partial Causal and Argument Map (Signed digraph) Crested from Causal Matrix of a Decision Maker (DM \#1)

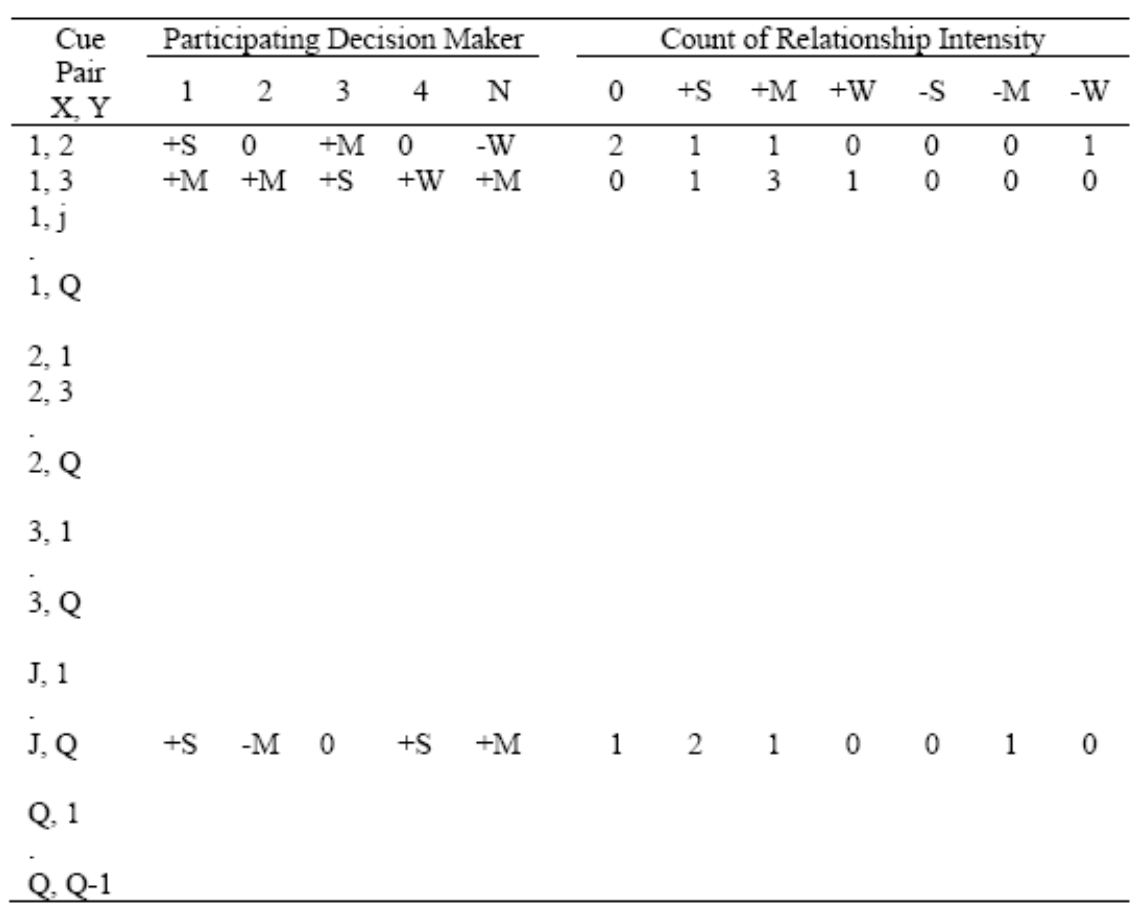

Figure 8. Causal Matrix of Group 


\begin{tabular}{lccccc}
\hline & $\begin{array}{c}\text { Cue } \\
1\end{array}$ & Cue 2 & $\ldots$ & Cue Q $\begin{array}{c}\text { Normalized } \\
\text { Eigenvector } \\
\text { (Cue weight) }\end{array}$ \\
\hline Cue 1 & 1 & $1 / 3$ & $\ldots$ & 3 & 0.218 \\
Cue 2 & - & 1 & $\ldots$ & 5 & 0.537 \\
& & & & & \\
Cue Q & & & & 1 & 0.105 \\
\hline
\end{tabular}

Figure 9. Cue Preference Matrix for Individual Decision Maker DM \#1

\begin{tabular}{llllcc}
\hline & Cue 1 Cue 2 & $\ldots$ & $\begin{array}{c}\text { Cue Q Normalized } \\
\text { Eigenvector } \\
\text { (Cue weight) }\end{array}$ \\
\hline Cue 1 & 1 & 5 & $\ldots$ & 3 & 0.548 \\
Cue 2 & & 1 & $\ldots$ & $1 / 2$ & 0.102 \\
& & & & & \\
Cue Q & & & 1 & 0.230 \\
\hline
\end{tabular}

\section{Figure 10. Cue Preference Matrix for Individual Decision Maker DM \#N}

The cues agreed to by the group may be conflicting in nature. For example, when deciding on a judgment policy to select the most effective public policy for improving the community of a town, some of the objectives are to increase housing, improve recreation programs, improve economic development by encouraging manufacturing industries, and reduce environmental pollution. Increasing housing development uses up land which reduces the availability of land necessary for establishing open air recreation programs, and industrial growth adversely affects the program to reduce pollution. We use the MCDM technique, AHP method, to optimize the problem involving conflicting cues or objectives and multiple decision makers with different priorities.

First, the weights for the cues are assessed by each decision maker by using an AHP software package such as ExpertChoice. Every decision maker's relative preferences of cues are displayed in a cue preference matrix (Figures 9 and 10). The normalized eigenvectors are estimated cue weights which are fed back to the decision makers to allow them to learn from each other's assessment of the cues. Categories map of the kind mentioned earlier in the paper are constructed (Figure 11) using each decision maker's cue weights. Since the estimated weights of individual decision-makers are normalized eigenvectors, it remains meaningful to compare all of these in one diagrammatic representation. The polygon shaped categories maps are superimposed on each other and projected on a public screen so that all members can locate their positions with respect to others and seek clarification about the cue weights using GSS based communication if they so desire. Revision of weights, if necessary, is carried out by using the AHP software, and revised categories map presented to all members once again. The iterative process continues until all decision makers are satisfied with their contributed cue weights. The individual sets of weights are then used in the geometric means approach to obtain group weights for the cues (Figure 12). 

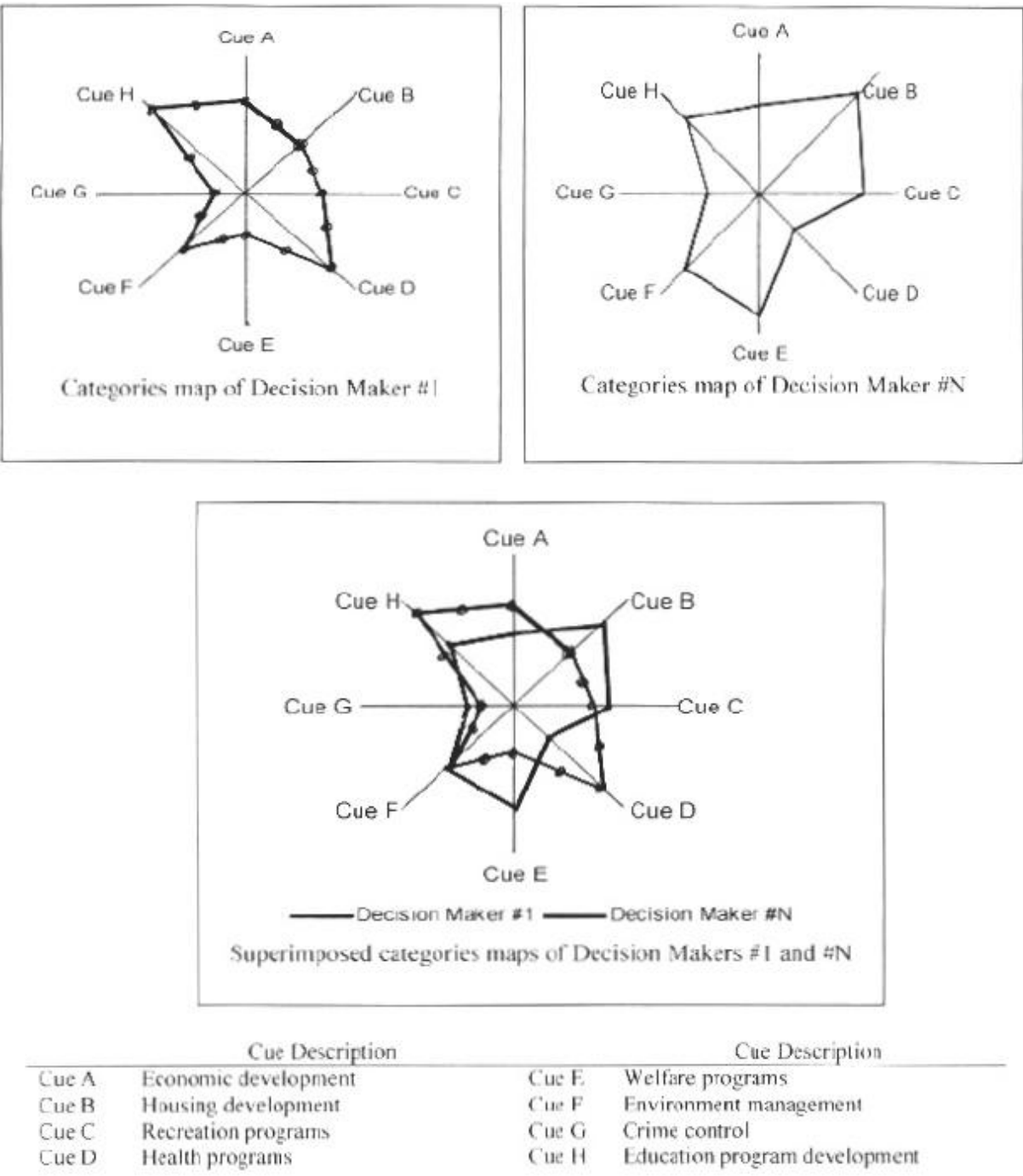

Figure 11. Categories Maps

The group cue weights and the corresponding cues are placed as a linear combination of cues according to the SJT model to represent the group judgment policy for evaluating various alternatives to improve the community of a town. The group policy will be represented, using sample cue weights, as

$$
\mathrm{Y}_{\mathrm{j}}=0.227 \mathrm{x}_{\mathrm{j} 1}+0.421 \mathrm{x}_{\mathrm{j} 2}+\ldots \ldots+0.208 \mathrm{x}_{\mathrm{jQ}}
$$

where $Y_{j}$ is the judgment of the group for an alternative proposal $\mathrm{j}$ and,

$\mathrm{x}_{\mathrm{j} 1}=$ value of economic development, \$million / year

$\mathrm{x}_{\mathrm{j} 2}=$ value of housing development, Units of housing / year 
$\mathrm{x}_{\mathrm{Jq}}=$ value of education programs, \$million / year

all of which are measured for alternative $\mathrm{j}$ being evaluated.

\begin{tabular}{lcccccc}
\hline & Cue 1 & Cue 2 & $\ldots$ & Cue Q $\begin{array}{c}\text { Normalized } \\
\text { Eigenvector } \\
\text { (Cue weight) }\end{array}$ \\
\hline Cue 1 & 1 & 0.776 & $\ldots$ & 1.216 & 0.227 \\
Cue 2 & - & 1 & $\ldots$ & 0.693 & 0.421 \\
& & & & & \\
Cue Q & & & & 1 & 0.208 \\
\hline
\end{tabular}

The values in the columns labeled Cue 1 through Cue $Q$ are geometric means of the corresponding values of individual decision makers

Figure 12. Cue Preference Matrix for Group of Decision Makers

\section{Conclusions}

Analysis of cognitive conflict tasks can be based on an approach to cognition and social interaction as explained in Social Judgment Theory. The focus of the theory is on the difficulty inherent in the task of integrating complex, probabilistic information from a variety of sources as well as differing cognitive orientation of decision makers in order to arrive at a harmonious decision. One example where applying cognitive conflict theory in a judgment and decision-making perspective can be beneficial is on the topic of managing threats to democracy (Mandel 2005). In order for a group of decision makers to agree with respect to their judgments, they must agree about or be able to reach a compromise on principles and they must be able to make their judgments in a reliable, consistent manner.

We have proposed a GSS that uses social judgment analysis and decision-analytic aids such as cognitive mapping and multiple criteria decision making to support cognitive-conflict tasks. Cognitive maps are applied in the architecture to provide feedback at various steps of the process to help the participants better understand and compromise to reach a consensus. The AHP multicriteria decision making method has been applied to assess the conflicting cues in the judgment policy being considered by the decision makers. The final product is a group judgment policy for a cognitive-conflict task where it is expected that the members have a good understanding of the complexity of the policy, and the ability to use it consistently on tasks in the same problem domain. Since the group process involves extensive sharing of information, we expect it to improve group judgment accuracy as well. We plan to test the proposed GSS architecture to evaluate its impact on constructing group judgments in a future research study. Another research idea is to explore the impact of factors such as outcome feedback and cue redundancy on policy inconsistency that were reported by Karelaia and Hogarth (2008) but now in the context of cognitive conflict research. Dhami and Olsson (2008) suggest to take advantage of the technological advances and use them to develop and test new theories based on judgment and decision making body of knowledge. Even though GSS or the other tools we use in our framework are not the latest among the technological innovations, the integration of those tools as proposed by us is innovative. 
Though there are several optimization models in management science, most complex policy problems commonly subject to cognitive conflicts require support by computerized systems that have an integration of decision-aids to process factual information, values, goals, and preferences of decision makers. Cognitive conflict tasks should be supported by a system that will help people understand and communicate cognitive processes. The architecture that has been described here encompasses a set of interactive decision-aids that (a) externalize and communicate value functions; (b) provide needed factual information and projections; (c) allow for an integration of facts and values; (d) provides for a tracking and feedback mechanism that can be used to assess sensitivity to changes in assumptions about either factual information or the values of the decision makers; and (e) order the preferences of decision makers. The proposed architecture can be used not only to help organize and manage the flow of information regarding cognitive conflict tasks, but also to provide decision makers with a framework for assessing and communicating their judgment policies, thus leading to more consistent, and more satisfying, consensus judgments.

\section{References}

1 Anderson, N.H. (1986). A cognitive theory of judgment and decision. In B. Brehmer, H. Jungermann, P. Lourens, and G. Sevon (Eds.), New Directions in Research on Decision Making. North-Holland: Amsterdam,

2 Axelrod, R.M. (Ed.). (1976). The structure of decision: Cognitive maps of political elites. Princeton University Press: Princeton, NJ.

3 Bose, U., \& Paradice, D. B. (1999). The effects of integrating cognitive feedback and multi-attribute utility-based multicriteria decision-making methods in GDSS. Group Decision and Negotiation, 8, 157-182.

4 Bougon, M.G. (1983). Uncovering cognitive maps - The Self-Q technique. In G. Morgan (Ed.), Beyond Method: Strategies for Social Research. (pp. 173-188). Sage Publications: Thousand Oaks, CA.

5 Brunswik, E. (1955). Representative design and probabilistic theory in functional psychology. Psychological Review, 62, 193-217.

6 Cook, R.L., \& Hammond, K.R. (1982). Interpersonal learning and interpersonal conflict reduction in decision-making groups. In R.A. Guzzo (Ed.), Improving Group Decision Making in Organizations: Approaches from Theory and Research. Academic Press: New York, NY.

7 Dhami, M.K., \& Olsson, H. (2008). Evolution of the interpersonal conflict paradigm. Judgment and Decision Making, 3(7), 547-569.

8 Doherty, M.E., \& Balzer, W.K. (1988). Cognitive feedback. In B. Brehmer, and C.R.B. Joyce (Eds.), Human Judgment: the SJT View. North-Holland: Amsterdam.

9 Eden, C., \& Ackermann, F. (2004). Cognitive mapping expert views for policy analysis in the public sector. European Journal of Operational Research, 152, 615630.

10 Eden, C., Ackermann, F. (1998). Making Strategy: The Journey of Strategic Management. Sage Publications: London, England.

11 Edkins, A.J., Kurul, E., Maytorena-Sanchez, E., \& Rintala, K. (2007). The application of cognitive mapping methodologies in project management research. International Journal of Project Management. 25, 762-772. 
12 Fedrizzi, M., \& Pasi, G. (2008). Fuzzy logic approaches to consensus modelling in group decision making. In D. Ruan, F. Hardeman and K. van der Meer (Eds.), Intelligent Decision and Policy Making Support Systems. (pp. 19-37). Springer: Berlin, Germany.

13 Fiol, C.M., \& Huff, A.S. (1992). Maps for managers: where are we? Where do we go from here? Journal of Management Studies, 29(3), 267-285.

14 Hammond, K.R. (1965). New directions in research on conflict resolution. Journal of Social Issues, 21, 44-66.

15 Harmon, J. (1998). Electronic meetings and intense group conflict: Effects of a policy-modeling performance support system and an audio communication support system on satisfaction and agreement. Group Decision and Negotiation, 7, 131-155.

16 Harmon, J., \& Rohrbaugh, J. (1990). Social judgment analysis and small group decision making: Cognitive feedback effects on individual and collective performance. Organizational Behavior and Human Decision Processes, 46, 34-54.

17 Huff, A.S. (1990). Mapping strategic thought. In A.S. Huff (Ed.), Mapping Strategic Thought. Wiley: New York, NY.

18 Hursch, C.J., Hammond, K.R., \& Hursch, J.L. (1964). Some methodological considerations in multiple-cue probability studies. Psychological Review, 71, 42-60.

19 Jackson, P., \& Webster, R. (2007). The social reality of business activity: A contingent methodology for knowledge elicitation and mapping. International Journal of Knowledge Management, 3(1), 49-65.

20 Karelaia, N., \& Hogarth, R. M. (2008). Determinants of linear judgment: a metaanalysis of lens studies. Psychological Bulletin, 134, 404-426.

21 Langfield-Smith, K. (1992). Exploring the need for a shared cognitive map. Journal of Management Studies, 29(3), 349-368.

22 Lehrer, K., \& Wagner, C. (1981). Rational Consensus in Science and Society. D. Reidel Publishing Company: Dordrecht, Holland.

23 Lim, J., \& Guo, X. (2008). A study of group support systems and the intergroup setting. Decision Support Systems, 45(3), 452-460.

24 Mandel, D.R. (2005). Threats to democracy: A judgment and decision-making perspective. Analyses of Social Issues and Public Policy, 5, 209-222.

25 McGrath, J.E. (1984). Groups: Interaction and Performance. Prentice-Hall: Englewood Cliffs, NJ.

26 Reagan-Cirincione, P. (1994). Improving the accuracy of group judgment: A process intervention combining group facilitation, social judgment analysis, and information technology. Organizational Behavior and Human Decision Processes, 58, 246-270.

27 Paul, S., Haseman, W.D., \& Ramamurthy, K. (2004). Collective memory support and cognitive-conflict group decision-making: An experimental investigation. Decision Support Systems, 36, 261-281.

28 Rains, S.A. (2007). The impact of anonymity on perceptions of source credibility and influence in computer-mediated group communication: A test of two competing hypotheses. Communication Research, 34(1), 100-125.

29 Saaty, T.L. (1980). The Analytic Hierarchy Process. McGraw-Hill: New York, NY.

30 Saaty, T.L., \& Vargas, L.G. (1982). The Logic of Priorities. Kluwer-Nijhof: Boston, MA. 
31 Sengupta, K., \& Te'eni, D. (1993). Cognitive feedback in GDSS: Improving control and convergence. MIS Quarterly, 17(1), 87-113.

32 Shapiro, G. (1997). The future of coders: Human judgments in a world of sophisticated software. In C.W. Roberts (Ed.), Text Analysis for the Social Sciences: Methods for Drawing Statistical Inferences from Texts and Transcripts. Lawrence Erlbaum Associates: Mahwah, NJ.

33 Sherman, J.W., Klein, S.B., \& Wyer, N.A. (1998). Intergroup bias in group judgment processes: The role of behavioral memories. Journal of Experimental Social Psychology, 34(1), 51-65.

34 Tegarden, D.P., \& Sheetz, S.D. (2003). Group cognitive mapping: A methodology and system for capturing and evaluating managerial and organizational cognition. Omega: The International Journal of Management Science, 31, 113-125.

35 Tucker, L.R. (1964). A suggested alternative formulation in the developments by Hursch, Hammond and Hursch, and by Hammond, Hursch and Todd. Psychological Review, 71, 528-530.

36 Vathanophas, V., \& Liang, S.Y. (2007). Enhancing information sharing in group support systems (GSS). Computers in Human Behavior, 23(3), 1675-1691. 